\title{
The effect of patterns of partial reinforcement upon the response to frustrative non-reward ${ }^{1,2}$
}

\author{
JOSEPH H. GROSSLIGHT, FLORIDA STATE UNIVERSITY \\ DAVID C. RICCIO, WESLEY C. ZAYNOR AND MICHAEL ROHRBAUGH, KENT STATE UNIVERSITY
}

Three groups of rats received different patterns of reinforcement-nonre inforcement (RR, RU, UR) in GB1 of an Amseltype double runway. On the basis of a previous observation, it was predicted that IIR trained animals would show less frustration effect (i.e., less increment in running speed in Section II) when tested following frustrative non-reward in G31. The prediction was confirmed by a latency measure only.

Grosslight and associates $(1953,1955,1957)$ have demonstrated that non-reinforcement must be followed by at least a single reinforcement in order to produce the increased persistence characteristic of partial reinforcement in discrete trial situations. It was found that differential performance on a habit reversal test was related to the following patterns of reinforcement on the last two trials of daily training sequences: continuous reinforcement (RR); non-reinforcementreinforcement (UR); and reinforcement-non-reinforcement (RU) (1957).

A previously unreported observation is the basis for the present research. During the habit-reversal test for patterning effect, it was noted that the UR trained animals not only took longer to reverse but were considerably less agitated and less prone to escape when detained in the non-reinforced goal box. Thus, it seemed possible that the pattern of reinforcement may be one determinant of the somewhat vaguely defined concept of "frustration tolerance."

Amsel (1952, 1962) has proposed that frustrative non-reward produces a motivational enhancement which is reflected in faster running speed in a second section of a straight runway when non-reinforcement rather than reinforcement has occurred in the prior goal box.

The Grosslight observation suggests that animals trained in the Amsel two-section runway according to the three patterns of reinforcement (RR, RU, UR) will show different responses to the frustration test situation (i.e., non-reinforcement in GB1). Specifically, it is predicted that the UR trained group will show the least increase in running speed following non-reinforcement and that RU performance will be more like RR than UR (1955).

Method

Subjects. Subjects were 45 male Holtzman rats approximately 90 days old at the beginning of the experiment. Three groups of 15 animals each were established on the basis of comparable running speeds on the last two trials of preliminary training.

Apparatus. The apparatus was a straight runway with GB1 36 in. from the start box and GB2 124 in. from GB1.
The straightway was essentially a duplicate of the one used by Wagner (1959), except that the floor in the first section was smooth and painted black. Starting and running times were obtained in the following manner: $E$ simultaneously opened the start door and pushed a button which activated three standard electric timers in that runway. Each clock was stopped when $S$ interrupted a light beam to a photoelectric cell. Photocells were located $5-3 / 4$ in., 11-3/4 in., and 19-3/4 in. from the start box door in Section I, and 3-1/2 in., 12 in., and 108 in. in Section II.

Procedure. Animals were housed in groups of five but were fed in large gang cages. Ss were handled and given feeding experience with P. J.Noyes $45 \mathrm{mg}$ pellets. After initial weight levels were obtained Ss were deprived and maintained at $80 \%$ of body weight throughout the experiment.

Initial adaptation to the apparatus consisted of $5 \mathrm{~min}$. of free exploration with all doors open for three days. This was followed by two trials per day for two days in which each $S$ was placed in GBs 1 and 2 and allowed to eat two Noyes pellets. Finally, animals were given two runs per day for two days from each start box to each goal box.

Training. Ss received 12 days of training with 4-6 massed trials per day, totaling 50 trials. A typical day's schedule is represented in Table 1.

In Table $1 \mathrm{R}-\mathrm{R}$ refers to successive reinforcement in both goal boxes, $\mathrm{R}$ to reinforcement in $\mathrm{GB1}$ followed by removal from the maze, and $U$ to non-reinforcement in GB1 followed by removal from the maze. The $U$ event for RU Ss was always the last trial for the day; whereas for the UR Ss it was always the trial preceding the last one. All non-reinforced trials occurred in GB1. The number of trials terminating in GB1 was held constant across groups. Ss were detained in goal boxes for $20 \mathrm{sec}$. regardless of reinforcement condition.

Squads of 15 rats, five animals from each group, were run by each of three experimenter-teams. Following daily training, each rat was held in an individual cage

Table 1. Representative Reinforcement/Non-Reinforcement Schedule

\begin{tabular}{cccc} 
Trial & R-R & $\begin{array}{c}\text { Group } \\
\text { U-R }\end{array}$ & R-U \\
\hline 1 & R-R & R-R & R-R \\
2 & $R$ & $R$ & $R$ \\
3 & $R-R$ & R-R & R-R \\
4 & $R$ & $U$ & R-R \\
5 & R-R & R-R & U \\
\hline
\end{tabular}


and subsequently placed in the large feeding cage $15 \mathrm{~min}$. after the entire squad had been run.

Test. Animals were given five test trials per day over six days. Each test trial consisted of non-reinforcement in Goal Box 1 (20 sec. hold) and reinforcement in Goal Box 2. Response latencies and running times in both sections of the maze were recorded.

\section{Resulis and Discussion}

Group results are based on the mean of the median performance for each animal on each test day. Individual results were calculated as a difference score between the median performance on any test day and the median performance of the last two days (Days 11 and 12) of training. In this fashion, differences in training performance among Ss are taken into consideration.

An analysis of variance of difference scores over three days for total traversal time (response latencies and running time) in the second section fails to show a significant treatment effect $(F=1.73 ; \mathrm{df}=2 / 42)$. Initially neither the Amsel frustration effect nor the main hypothesis appear to be supported. However, when the total time performance in the second runway is analyzed into its component parts, a very different result is obtained. An analysis of variance of median difference scores for latencies, i.e., time from opening of start box of GB1 to first light beam in Section II, yields a significant treatment effect $(F=3.45 ; p<.05)$. An examination of the curves (Fig. 1) supports the differential frustration hypothesis of the reinforcement pattern effect: UR animals are slower to leave GB1. A NewmanKeuls test indicated that the significant effect is between UR and RR with RU not significantly different from either group $(\mathrm{p}<.05)$.

It is apparent that the effect of frustration upon subsequent performance is rather complex. These results further emphasize that the consequence of nonreinforcement is related to its aftereffect in interaction with subsequent events. It must be noted that our procedure is quite different from that typically used by

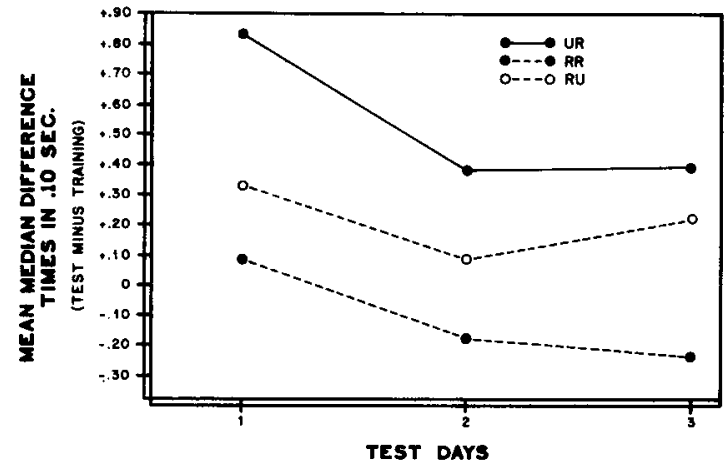

Fig. 1. Difference Latencies in Section II of Runway for Three Patterns of Reinforcement.

Amsel and associates. Our situation involves training followed by tests in extinction; the Amsel tests, on the other hand, compare running speeds following a nonreinforced trial interspersed among reinforced trials.

\section{References}

Amsel, A., \& Roussel, J. Motivational properties of frustration: Effect on a running response of the addition of frustration to the motivational complex. J. exp. Psychol., 1952, 43,363-368.

Amsel, A. Frustrative nonreward in partial reinforcement and discrimination learning: Some recent history and a theoretical extension. Psychol. Rev., 1962, 69:4, 306-328.

Grosslight, J. H., Hall, J. F., \& Mumin, J. Patterning effect in partial reinforcement. $J$. exp. Psychol., 1953, 46, 103-106. Grosslight, J. H., \& Radlow, R. Patterning effect of the nonreinforcement-reinforcement sequence in a discrimination situation. J. comp. physiol. Psychol., 1955, 49, 543-547.

Grosslight, J. H., \& Radlow, R. Patterning effect of the nonreinforcement-reinforcement sequence involving a single nonreirforced trial. J. comp. physiol. Psychol., 1957, 50, 23-25.

Wagner, A. R. The role of reinforcement and nonreinforcement in an "apparent frustration effect." $J$. exp. Psychol., 1959, 57, 130-136.

\section{Notes}

1. The authors wish to recognize the major assistance of Mrs. Fred Coulter in this research.

2. Portions of this paper will be presented at Psychonomic Society Meeting, St. Louis, 1966. 